УДК $378.4 ; 303.722$

\title{
ИНСТИТУЦИОНАЛЬНЫЕ ОСНОВЫ УПРАВЛЕНИЯ ОБРАЗОВАНИЕМ ЛИЦ С ОГРАНИЧЕННЫМИ ВОЗМОЖНОСТЯМИ
}

\author{
А.В. ЦЕЛИКИН \\ старший преподаватель ФГБОУ ВПО \\ «Российский государственный социальный университет», г. Москва, Россия
}

\begin{abstract}
Аннотация
Статья посвящена рассмотрению экономико-правовых аспектов развития образования, доступного для лиц с ограниченныли возможностями. В ней рассмотрены институциональные основы формирования социальной среды образования.

Ключевые слова: образование, инвалиды, право, управление образованием, лииа с ограниченными возможностями
\end{abstract}

Abstract

The article is devoted to consideration to the economic and legal aspects of the education progress, access persons with disabilities. It regards the organizational institutional framework of formation of social of the education environment.

Keywords: education, disabilities, law, education, persons with disabilities

\section{ВВЕДЕНИЕ}

Ратификация Российской Федерацией Конвенции о правах инвалидов, которая была принята резолюцией 61/106 Генеральной Ассамблеи ООН от 13 декабря 2006 года (15 мая 2012 года вступил в силу Федеральный закон № 46-Ф3 «О ратификации Конвенции о правах инвалидов») определяет обязательства государства не только по разработке новых законов, защищающих права людей-инвалидов и изменении существующих законов имеющих признаки дискриминации, но и разработке организационноэкономического механизма их практического применения.

По данным ООН во многих странах мира, в том числе и в России лица с инвалидностью сталкиваются с серьезными физическими, социальными и экономическими барьерами, ограничивающими их доступ к услугам в сфере здравоохранения, образования, занятости и транспорта. Они в наибольшей степени страдают в результате безработицы и бедности [1].

Несмотря на недостаточность данных о численности молодых людей с ограниченными возможностями, по приблизительным оценкам ООН их численность в мире составляет от 180 до 220 млн. человек, а эксперты ООН подчеркивают, что, так как половину населения планеты составляют лица в возрасте младше 15 лет [2], число девушек и юношей с инвалидностью, имеющих проблемы образования и работы по специальности, в ближайшие годы возрастет, особенно в странах с низким и средним уровнем дохода. Что в условиях экономического кризиса в России, отражающегося, в том числе, на ограничении средств федерального и регионального бюджетов, направляемых на реализацию социальных программ, может привести к снижению качества жизни лиц с ограниченными возможностями, и соответственно, росту социальной напряженности.

Несмотря на то, что по официальным данным Росстата и Минтруда России за последние 10 лет количество лиц с инвалидностью младше 18 лет снижается (с 1109 тыс.чел. в 2000 году, до 754000 чел. в 2013 году), по данным независимых экспертов это не совсем точные данные, что связано, во-первых, с ужесточением государ- 
ственного учета инвалидов, во-вторых, - с учетом в системе государственной статистики только инвалидов, получивших право на государственную пенсию и льготы, что косвенно подтверждается существенной разницей между долей лиц с ограниченными возможностями среди общей численности населения зарегистрированной в ЕС и России.

А по данным научных исследований, проведенных в начале XXI века Кулагиной Е.В., численность детей-инвалидов в России увеличилась в 12 раз (около 0,6 млн. семей с детьми-инвалидами с тенденцией к росту до $1,2-1,5$ млн. человек) [3].

Таким образом, сочетание различных политических, экономических и социокультурных факторов, таких как повышение социальных обязательств государства по отношению к лицам с ограниченными возможностями в связи с ратификацией соответствующих международных нормативно-правовых документов и реформа системы высшей школы в условиях экономического кризиса и роста безработицы, включая скрытую безработицу, а также активные миграционные процессы в ЕАЭС, обусловливают необходимость разработки соответствующего организационно-экономического механизма управления высшим образованием лиц с ограниченными возможностями с целью их полноценной социализации и социальной адаптации с повышением их качества жизни, включая повышение доступности высшего образования и возможности трудоустройства по специальности, ростом их социальной защищенности и увеличением качества трудовых ресурсов страны.

При этом под понятием «лица с ограниченными возможностями» в контексте парадигмы инклюзивного образования мы понимаем не только лиц с инвалидностью, но и представителей молодежи, в силу низкого уровня образованности, недостаточности знания русского языка и других причин социального характера сталкивающихся с препятствиями в получении высшего образования и трудоустройства в Российской Федерации и с дискриминацией по образовательному или интеллектуальному признаку.

Несмотря на то, что в последние годы государственными органами законодательной и исполнительной власти предпринимаются попытки поднять систему российского высшего образования на более высокий уровень качества, посредством изменения организационных форм, содержания образовательных стандартов и учебных программ, применения современных информационно-образовательных технологий, сегодня учреждения высшего образования сталкиваются с такими проблемами, как несоответствие нормативных требований существующих образовательных стандартов ресурсным возможностям образовательных учреждений, отсутствием профессионального опыта у научно-педагогических работников по обучению лиц с ограниченными возможностями, научно-методической базы внедрения нормативных требований, регламентированных Федеральным законом «Об образовании в Российской Федерации» и новыми образовательными стандартами в области обеспечения доступности образовательной среды и качества образования для лиц с инвалидностью. Кроме того, сохраняется недовольство общества качеством профессионального образования и результатами действий, направленных на решение данной проблемы.

Образовательные учреждения, являясь экономически, юридически и административно зависимыми от государственных органов управления образованием, стоят перед необходимостью решать достаточно трудные задачи сочетания соответствия государственным образовательным стандартам и созданием учебного продукта, обеспечивающего качественную подготовку в будущем конкурентоспособного специалиста по выбранной специальности на рынке труда, являющегося лицом с ограниченными возможностями.

В условиях интеграции России в мировое образовательное пространство повышение качества высшего образования и обеспечение равного доступа к высшему образованию независимо от физических, интеллектуальных или иных особенностей 
граждан позволит повысить конкурентоспособность отечественной экономики и снизит социальную нагрузку на федеральные и региональные бюджеты.

Проблема повышения качества управления системой высшего образования в контексте парадигмы инклюзивного образования является комплексной, связанной с необходимостью учета интересов прямых и косвенных акторов образовательного процесса.

Теоретические основы развития теории качества экономических объектов были заложены в работах Аристотеля, Л. Вальраса, У. Джевонсона, Д. Локка, В. Парето, П. Самуэльсона и др.

Вопросы оценки качества, эффективности, результативности образовательной деятельности освещены в трудах таких видных ученых в области управления высшим профессиональным образованием, как Солонин С.И., Азарова Р.Н., Богословский В.А., Борисова Н.В., Галямина И.Г., Дунченко Н.И., Золотарева Н.М., Кузов В.Б., Лабутина Н.В., Мелехова О.П., Алексеенко В.А., Бадарч Д., Сазонов Б.А., Шматков Р., Гретченко А.И., Гретченко А.А., Аванесов В.С., Байденко В.И., Бездудная А.Г., Белобрагин В.Я., Боголюбов В.С., Будрина Е.В., Васильев Ю.С., Глухов В.В., Лапушинская Г.К., Новиков А.М, Новиков Д.А., Субетто А. И., Ходачек А. М., Шимко П.Д., Чекалин В.С., Чекмарев В.В.

Вопросы социализации и социальной адаптации рассмотрены в трудах Э. Дюркгейма, Р. Мертона Р. Парка, П. Сорокина, Д. Зайцева, С. Степухович, Е. Мавриной, О. Тимуцы, Е.Холостова.

Исследователи теории социальной работы Т.И.Черняева, Н.В. Шапкина, С.В. Степухович, Е.Р. Ярская - Смирнова, а также зарубежные ученые, такие как A. Kleinman, развивают социокультурный подход к проблеме инвалидности. Социально-правовой статус инвалидов представлен в работах П. Н. Любченко, В.В. Лябина, С.Н. Кавокина, Т.М. Пушкиной, Н.Ф. Дементьевой, Э.В.Устиновой.

Вопросы социальной, профессиональной, социокультурной реабилитации инвалидов освящены в работах современных отечественных ученых: Н.В. Веденеевой, О.Г. Злобиной, И.А. Дворянчиковой, Е.В. Толкачёвой.

Однако следует отметить недостаточность системных научных исследований по вопросам организации обучения лиц с ограниченными возможностями в учреждениях высшего образования.

\section{РЕЗУЛЬТАТЫ И ИХ ОБСУЖДЕНИЕ}

Основой развития социализации лиц с ограниченными возможностями является нормативно-правовая база федерального, регионального и муниципального уровней, а также международные нормативно-правовые акты и рекомендации принятые Российской Федерацией. Она определяет правила обучения и требования к функционированию образовательных учреждений с учетом личностных различий обучающихся и их потребностей.

Так, в статье 43 Конституции Российской Федерации гарантируется каждому гражданину России право на образование, вне зависимости от его физических возможностей, что предполагает необходимость формирования определенных условий, обеспечивающих обучение лиц с ограниченными возможностями, включая приобретение и использование соответствующего специализированного оборудования и создания определенных учебных заведений, специализирующихся на обучении лиц с ограниченными возможностями.

Тем более, что в этой же статье государством «гарантируются общедоступность и бесплатность дошкольного, основного общего и среднего профессионального образования в государственных или муниципальных образовательных учреждениях 
и на предприятиях», а родители или лица их заменяющие обязаны обеспечить условия для их соответствующего обучения [4]. Что касается высшего образования, то Конституция РФ гарантирует возможность его получения на конкурсной основе, при этом лица с ограниченными возможностями имеют определенные льготы.

Как уже упоминалось, ратифицированная Российской Федерацией Федеральным законом № 46-Ф3 «О ратификации Конвенции о правах инвалидов» от 03 мая 2012 года [5] Конвенция о правах инвалидов от 13 декабря 2006 года, подписанная от имени Российской Федерации в городе Нью-Йорке 24 сентября 2008 года, предусматривает обязанность государства обеспечить инвалидов возможностями для получения ими высшего образования и в дальнейшем эффективного участия в общественной жизни, включая трудовую деятельность.

В статье 19 Федерального закона от 24.11.1995 года № 181-Ф3 (ред. от 28.12.2013) «О социальной защите инвалидов в Российской Федерации» также гарантируется государственная поддержка обучения лиц с ограниченными возможностями с целью реализации гарантированных им государством конституционных прав и свобод, обеспечение условий для всестороннего развития личности и их социализации.

Обязанность по обеспечению условий для выполнения нормы закона возложена в этой же статье Федерального Закона на органы, осуществляющие управление в сфере образования, социальной защиты населения, здравоохранения и образовательные организации, включая получение инвалидами общедоступного и бесплатного дошкольного, начального общего, основного общего, среднего общего образования и среднего профессионального образования, а также бесплатного (на бюджетной основе) высшего образования для инвалидов I и II групп [6].

При этом предусматривается необходимость разработки и использования адаптированных образовательных программ и индивидуальных программ реабилитации лиц с ограниченными возможностями (включая создание специальных профессиональных образовательных учреждений различных типов и видов или соответствующих условий в профессиональных образовательных учреждениях общего типа), информирования лиц с ограниченными возможностями и их родителей (законных представителей) по вопросам получения общего и профессионального образования, а также профессионального обучения, оказания психолого-педагогической поддержки при получении лицами с ограниченными возможностями образования, в том числе при получении общего образования детьми-инвалидами на дому и в форме семейного образования, создание необходимых условий для получения образования в организациях, осуществляющих образовательную деятельность по реализации основных общеобразовательных программ, в которых созданы специальные условия для получения образования обучающимися с ограниченными возможностями здоровья, а также в отдельных организациях, осуществляющих образовательную деятельность по адаптированным основным общеобразовательным программам, доступа к образовательной инфраструктуpe, приспособления помещений, мебели, оборудования к возможностям инвалидов в соответствии с требованиями нормативов безбарьерной архитектуры, при необходимости адаптация программ обучения к психофизиологическим особенностям инвалидов и педагогическая коррекция учебного процесса, предоставление возможности слабослышащим инвалидам пользоваться услугами сурдопереводчиков [7; 8; 9].

Вступивший в силу с 1 сентября 2013 г. Федеральный закон от 29 декабря 2012 г. Ф3-273 «Об образовании в Российской Федерации» закрепляет безусловное право инвалидов, «то есть обучающихся с ограниченными возможностями здоровья, имеющих недостатки в физическом и (или) психологическом развитии, подтвержденные психолого-медико-педагогической комиссией и препятствующие получению образования без создания специальных условий» [9]. 
Применительно к праву получения высшего образования на льготной основе к лицам с ограниченными возможностями здоровья относятся следующие лица:

- глухие;

- слабослышащие;

- слепые;

- слабовидящие;

- с тяжелыми нарушениями речи;

- с нарушениями опорно-двигательного аппарата и др.

В статье 79 этого Закона, которая регламентирует организацию получения образования обучающимися с ограниченными возможностями здоровья, регламентируются нормы по реализации их прав в сфере образования, и провозглашается, что:

- «Содержание образования и условия организации обучения и воспитания обучающихся с ограниченными возможностями здоровья определяются адаптированной образовательной программой, а для инвалидов также в соответствии с индивидуальной программой реабилитации инвалида».

- «Образование обучающихся с ограниченными возможностями здоровья может быть организовано как совместно с другими обучающимися, так и в отдельных классах, группах или в отдельных организациях, осуществляющих образовательную деятельность».

- «Профессиональное обучение и профессиональное образование обучающихся с ограниченными возможностями здоровья осуществляются на основе образовательных программ, адаптированных при необходимости для обучения указанных обучающихся».

- «Профессиональными образовательными организациями и образовательными организациями высшего образования, а также организациями, осуществляющими образовательную деятельность по основным программам профессионального обучения, должны быть созданы специальные условия для получения образования обучающимися с ограниченными возможностями здоровья».

- «При получении образования обучающимся с ограниченными возможностями здоровья предоставляются бесплатно специальные учебники и учебные пособия, иная учебная литература, а также услуги сурдопереводчиков и тифлосурдопереводчиков. Указанная мера социальной поддержки является расходным обязательством субъекта Российской Федерации в отношении таких обучающихся, за исключением обучающихся за счет бюджетных ассигнований федерального бюджета. Для инвалидов, обучающихся за счет бюджетных ассигнований федерального бюджета, обеспечение этих мер социальной поддержки является расходным обязательством Российской Федерации» [9].

В соответствии с приказом Министерства образования и науки Российской Федерации от 28 декабря 2011 г. № 2895 «Об утверждении порядка-приема граждан в образовательные учреждения высшего профессионального образования» граждане «с ограниченными возможностями здоровья в случае отсутствия у них результатов ЕГЭ при поступлении в высшие учебные заведения сдают вступительные испытания, определенные вузом в соответствии с Перечнем вступительных испытаний, и дополнительные вступительные испытания (в случае их наличия в вузе) в форме, установленной вузом самостоятельно, с учетом особенностей психофизического развития, индивидуальных возможностей и состояния здоровья (далее - индивидуальные особенности) таких поступающих» [10].

При проведении вступительных испытаний в соответствии с данным нормативным актом образовательные учреждения обеспечивают «соблюдение следующих тре- 
бований в зависимости от категорий поступающих с ограниченными возможностями здоровья:

а) для слепых:

- задания для выполнения на вступительном испытании, а также инструкция о порядке проведения вступительных испытаний оформляются рельефно-точечным шрифтом Брайля или в виде электронного документа, доступного с помощью компьютера со специализированным программным обеспечением для слепых, или зачитываются ассистентом;

- письменные задания выполняются на бумаге рельефно-точечным шрифтом Брайля или на компьютере со специализированным программным обеспечением для слепых, или надиктовываются ассистенту.

б) для слабовидящих:

- обеспечивается индивидуальное равномерное освещение не менее 300 люкс;

- для выполнения задания при необходимости предоставляется увеличивающее устройство;

- задания для выполнения, а также инструкция о порядке проведения вступительных испытаний оформляются увеличенным шрифтом.

в) для глухих и слабослышащих обеспечивается наличие звукоусиливающей аппаратуры коллективного пользования, при необходимости поступающим предоставляется звукоусиливающая аппаратура индивидуального пользования.

г) для лиц с тяжелыми нарушениями речи, глухих, слабослышащих все вступительные испытания по желанию поступающих могут проводиться в письменной форме;

д) для лиц с нарушениями опорно-двигательного аппарата (тяжелыми нарушениями двигательных функций верхних конечностей или отсутствием верхних конечностей) письменные задания выполняются на компьютере со специализированным программным обеспечением или надиктовываются ассистенту» [10].

В последних федеральных образовательных стандартах третьего поколения (3+) созданию условий для обучения инвалидов, впервые для такого типа документов, также уделяется достаточное внимание. Так, например, в соответствии с Приказом Министра образования и культуры Российской Федерации «Об утверждении федерального государственного образовательного стандарта высшего образования по направлению подготовки 38.03.02 Менеджмент (уровень бакалавриата)», в свою очередь в соответствии с пунктом 5.2.41 Положения о Министерстве образования и науки Российской Федерации, утвержденного постановлением № 466 Правительства Российской Федерации от 3 июня 2013 г. указано, что:

- для инвалидов и лиц с ограниченными возможностями здоровья выбор мест прохождения практик согласуется с требованием их доступности для данных обучающихся и состоянием здоровья;

- обучающиеся инвалиды и лица с ограниченными возможностями здоровья должны быть обеспечены печатными и электронными образовательными ресурсами в формах, адаптированных к ограничениям их здоровья;

- материально-техническая база образовательной организации должна быть доступна для обучающихся инвалидов и лиц с ограниченными возможностями здоровья;

- при организации инклюзивного образования инвалидов и лиц с ограниченными возможностями здоровья могут использоваться различные источники финансирования, не запрещённые законодательством Российской Федерации;

- как уже было рассмотрено ранее и продемонстрировано на примерах образовательная организация определяет требования к процедуре проведения государственных аттестационных испытаний с учетом особенностей этих процедур для инвалидов и лиц с ограниченными возможностями здоровья [11;12].

Следует отметить, что в мире основными документами, направляющими и регламентирующими образование лиц с ограниченными возможностями, являются: 1) Все- 
общая декларация прав человека, в статье 24 которой говорится о том, что каждый человек имеет право на образование, направленное к полному развитию человеческой личности и к увеличению уважения к правам человека и основным свободам, содействующее терпимости и дружбе между всеми народами, расовыми и религиозными группами; при этом техническое и профессиональное образование должно быть общедоступным, а высшее образование должно быть одинаково доступным для всех на основе способностей каждого [32]; 2) уже рассмотренная нами ранее Конвенция ООН «О правах инвалидов», принятая резолюцией 61/106 Генеральной Ассамблеи от 13 декабря 2006 года, European Disability Strategy (2010-2020). Согласно последнему документу ЕС должен обеспечить лицам с ограниченными возможностями:

1. Доступ к товарам, услугам и вспомогательным устройствам, транспорту, средствам и информационно-коммуникационным технологиям должен быть обеспечен таким же образом как и для здоровых людей.

2. Лица с ограниченными возможностями должны быть в состоянии полностью осуществить свои основные гражданские права, включая:

- преодоление препятствий подвижности лиц с ограниченными возможностями как потребителей, студентов, акторов экономических и политических процессов;

- получая качественное медицинское обслуживание;

- имея доступ к помещениям организаций, мест общего пользования и услуг.

3. Равенство лиц с ограниченными возможностями внутри государств-членов ЕС.

4. Возможность лицам с ограниченными возможностями здоровья реализовать свои компетенции на традиционном рынке труда, в том числе за счет улучшения доступности рабочих мест с учетом роста внутрипрофессиональной мобильности и развития самостоятельной предпринимательской деятельности [13].

\section{ВЫВОДЫ}

Несмотря на достаточно сформированную нормативно-правовую основу образования лиц с ограниченными возможностями, существуют объективные сложности правоприменительной практики в деятельности образовательных учреждений, особенно высшего образования, которые связаны:

- с недостаточностью материально-технической базы образовательных учреждений;

- с конструктивными особенностями зданий и сооружений, используемых в образовательном процессе учебными заведениями, которые не позволяют обеспечить доступную образовательную среду;

- с нехваткой квалифицированных кадров в образовательных учреждениях для организации учебного процесса с его адаптацией к индивидуальным особенностям лиц с ограниченными возможностями, включая разработку специализированных образовательных программ.

Это предполагает разработку четкой системы практической реализации требований российского законодательства в области обеспечения прав лиц с ограниченными возможностями, включая методологию и методические основы, организационноэкономический механизм управления образованием.

\section{ЛИТЕРАТУРА}

1. Конвенция ООН «О правах инвалидов», принятая резолюцией 61/106 Генеральной Ассамблеи от 13 декабря 2006 года

2. Материалы всемирного банка для учащихся [Электронный ресурс] / Режим доступа: http://www.un.org. - Дата доступа: 12.03.2015. 
3. Кулагина Е.В. Автореферат диссертации на соискание ученой степени кандидата экономических наук / Е.В.Кулагина. М.: ИСПЭН РАН, 2004 - 24c.

4. Конституция Российской Федерации: официальный текст с изменениями на 01.03.2012 года / Изд-во «Литера», СПб., 2012. - 64 с.

5. Федеральный закон № 46-Ф3 «О ратификации Конвенции о правах инвалидов» от 03 мая 2012 года.

6. Федеральный закон от 24.11.1995 года № 181-Ф3 (ред. от 28.12.2013) «О социальной защите инвалидов в Российской Федерации» [Электронный ресурс] / КонсультантПлюс. Режим доступа: http://www.consultant.ru/document/cons_doc_LAW_ 1567 92/?frame=3\#p376. - Дата доступа: 12.03.2014.

7. Гарантии инвалидам в сфере образования [Электронный ресурс] / Режим доступа: http://paralife.narod.ru/socialnaya-zashhita/obrazovanie-invalidov.htm. - Дата доступа: 12.03.2014.

8. Высшее и среднее специальное образование, профессиональная подготовка инвалидов Петербурге [Электронный ресурс] / Режим доступа: http://www.peterburg.biz/vyisshee-i-srednee-spetsialnoe-obrazovanie-professionalnaya-podgo tovka-invalidov-peter.html. - Дата доступа: 12.03. 2014.

9. Федеральный закон от 29 декабря 2012г. Ф3-273 «Об образовании в Российской Федерации» / Российская газета № 5976 от 31.12.2012г. - С. 1-10.

10. Гарантии инвалидам в сфере образования [Электронный ресурс] / Режим доступа: http://paralife.narod.ru/law/ob-utverzhdenii-poryadka-priema-grazhdan-v-obrazova telnye-uchrezhd eniya-2012.htm. - Дата доступа: 12.03.2014.

11. Приказ Министра образования и культуры Российской Федерации «Об утверждении федерального государственного образовательного стандарта высшего образования по направлению подготовки 38.03 .02 Менеджмент (уровень бакалавриата)».

12. Положение о Министерстве образования и науки Российской Федерации, утвержденного постановлением Правительства Российской Федерации от 3 июня 2013 г. № 466 / Собрание законодательства Российской Федерации, 2013, № 23, ст. 2923.

13. Всеобщая декларация прав человека (принята на третьей сессии Генеральной Ассамблеи ООН резолюцией 217 А (III) от 10 декабря 1948 г.) [Электронный ресурс] / Режим доступа: http://base.garant.ru/10135532/\#ixzz3jyMtfluq. Дата доступа: 12.03.2015.

14. Целикин, А.В. Нормативно-правовая база обучения лиц с ограниченными возможностями / А.В. Целикин // Технологии товароведческой, таможенной и криминалистической экпертизы: сборник научных трудов № 5. В 2ч. /под ред. д-ра экон.наук Г.Д. Дроздова, канд.техн.наук. А.П. Прошина - СПб.: изд-во СПбГЭУ, 2014. C.96-101.

Статья поступила в реакциию 11 ноября 2015 года. 